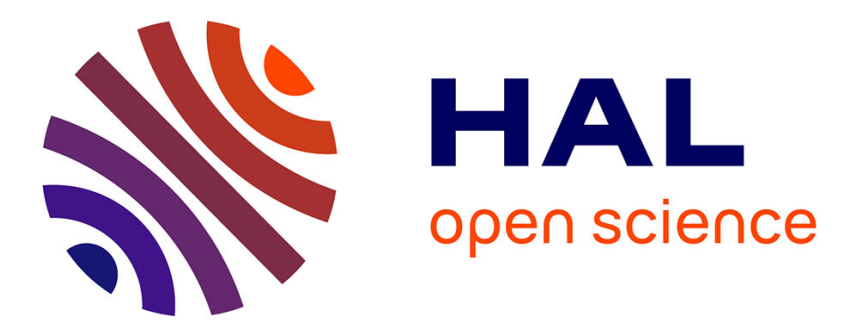

\title{
Attachment of $\beta$-Cyclodextrins on Cotton and Influence of $\beta$-Cyclodextrin on Ester Formation with BTCA on Cotton
}

Usha Rashmi Bhaskara, Audrey Tourrette, Dragan Jocic, Marijn M.C.G. Warmoeskerken

\section{To cite this version:}

Usha Rashmi Bhaskara, Audrey Tourrette, Dragan Jocic, Marijn M.C.G. Warmoeskerken. Attachment of $\beta$-Cyclodextrins on Cotton and Influence of $\beta$-Cyclodextrin on Ester Formation with BTCA on Cotton. AATCC Journal of Research, 2014, vol. 1, pp. 28-38. 10.14504/ajr.1.3.4 . hal-01095088

\section{HAL Id: hal-01095088 \\ https://hal.science/hal-01095088}

Submitted on 15 Dec 2014

HAL is a multi-disciplinary open access archive for the deposit and dissemination of scientific research documents, whether they are published or not. The documents may come from teaching and research institutions in France or abroad, or from public or private research centers.
L'archive ouverte pluridisciplinaire HAL, est destinée au dépôt et à la diffusion de documents scientifiques de niveau recherche, publiés ou non, émanant des établissements d'enseignement et de recherche français ou étrangers, des laboratoires publics ou privés. 


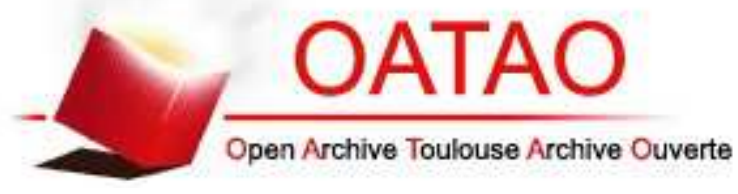

\section{Open Archive TOULOUSE Archive Ouverte (OATAO)}

OATAO is an open access repository that collects the work of Toulouse researchers and makes it freely available over the web where possible.

This is an author-deposited version published in : http://oatao.univ-toulouse.fr/ Eprints ID : 12072

To link to this article : DOI:10.14504/ajr.1.3.4

URL : http://dx.doi.org/10.14504/ajr.1.3.4

\section{To cite this version :}

Bhaskara, Usha Rashmi and Tourrette, Audrey and Jocic, Dragan and Warmoeskerken, Marijn M.C.G. Attachment of $\beta$-Cyclodextrins on Cotton and Influence of $\beta$-Cyclodextrin on Ester Formation with BTCA on Cotton. (2014) AATCC Journal of Research, vol. 1 ( $\left.\mathrm{n}^{\circ} 3\right)$. pp. 28-38. ISSN 2330-5517

Any correspondance concerning this service should be sent to the repository administrator: staff-oatao@ listes-diff.inp-toulouse.fr 


\title{
Attachment of $\beta$-Cyclodextrins on Cotton and Influence of $\beta$-Cyclodextrin on Ester Formation with BTCA on Cotton
}

\author{
By Usha Rashmi Bhaskara, University of Twente; Audrey Tourrette, University of Toulouse; Dragan Jocic, \\ University of Belgrade; and M. M. C. G. Warmoeskerken, University of Twente
}

\begin{abstract}
Cotton was treated with $\beta$-cyclodextrin (BCD) and two derivatives of $\beta$-cyclodextrin (2-hydroxypropyl- $\beta$-cyclodextrin and monochlorotriazinyl- $\beta$-cyclodextrin) to assess the optimal type for fixation with cotton. The experimental results showed that treatment of cotton with BCD using the crosslinker BTCA resulted in higher fixation than the treatments with the other two derivatives. The concentration of BTCA used did not significantly influence the amount of fixation of BCD on cotton. FTIR-ATR spectroscopic analysis showed that the amount of ester formed on the fabric was influenced by the addition of BCD on cotton with BTCA in comparison to crosslinking of only BTCA with cotton. The laundering tests showed relatively poor washfastness of the $\beta$-cyclodextrins on the fabrics.
\end{abstract}

Key Terms

$\beta$-Cyclodextrin, Cotton, BTCA, FTIR-ATR spectroscopy

\section{Introduction}

In this work, three different types of $\beta$-cyclodextrins ( $\beta$-cyclodextrin (BCD), 2-hydroxypropyl- $\beta$-cyclodextrin (HP BCD), and monochlorotriazinyl- $\beta$-cyclodextrin (MCT BCD) were attached to cotton. The aim of the work was to determine the optimum type of $\beta$-cyclodextrin for fixation on cotton and to check the influence of crosslinker concentrations on fixation of BCD on cotton. Additionally, the amount of ester formed on the fabric due to crosslinked BCD cotton cellulose was assessed. BCD in this work refers specifically to unmodified $\beta$-cyclodextrin, while $\beta$-cyclodextrins refers to modified and unmodified $\beta$-cyclodextrins in general and the three cyclodextrin types used in this work as a whole.

$\beta$-Cyclodextrins are cyclic oligosaccharides composed of glucose units linked by a-1,4-glycosidic bonds. Each $\beta$-cyclodextrin unit has a hydrophobic cavity that can act as a host for a hydrophobic guest molecule depending on the size, geometry, and molecular weight of the guest molecule. These types of host-guest complexes find application in control release of various drugs in the pharmaceutical industry and in other applications such as slow release of fragrances, aromatic oils, additives in the food industry, and so forth. Normally, a 1:1 complexation ratio is found between the cyclodextrin molecule and the guest molecule, while sometimes 1:2 or 2:1 ratios are also found. ${ }^{1}$ The inclusion of antimicrobial activity on textiles by incorporating antimicrobials as guest molecules in textilebound $\beta$-cyclodextrins are of particular interest.
Derivatives of $\beta$-cyclodextrin are formed by substituting hydroxyl groups with alkyl or hydroxyalkyl groups on the glucose units of the $\beta$-cyclodextrin molecule, leading to changes in solubility and complex-forming selectivity. ${ }^{2}$ HP BCD is one such derivative of $\beta$-cyclodextrin. The molecular weight of HP BCD is $1399 \mathrm{~g} / \mathrm{mol}$ as compared to $1135 \mathrm{~g} / \mathrm{mol}$ for BCD. ${ }^{3} \mathrm{HP}$ BCD is interesting due to its increased solubility in water as a result of the substituted hydroxyls with 2-hydroxypropyl groups in the anhydroglucopyranose units, due to which the inclusion complex forming ability is said to increase. Another popular derivative for fixation on textile is MCT BCD. MCT BCD, with an average molecular weight about $1560 \mathrm{~g} / \mathrm{mol}$, is particularly interesting because of the substitution of hydroxyls in the anhydroglucopyranose units with monochlorotriazinyl groups, which results in a compound that can be fixed to cotton without a crosslinker. ${ }^{4}$

In this investigation, $\mathrm{BCD}$ and $\mathrm{HP} \mathrm{BCD}$ were fixed to cotton via $1,2,3,4$, butanetetracarboxylic acid (BTCA) crosslinker. BTCA is a non-formaldehyde based crosslinker that has proven effective in terms of durable press performance in comparison with other polycarboxylic acids such as citric acid, malic acid, or succinic acid. BTCA has four carboxylic acid groups, one to three of which are said to be involved in crosslinking with cotton during the esterification reaction.

Cotton is known to esterify with BTCA during the curing process in two steps: first, by formation of a five-membered 
cyclic anhydride through the dehydration of adjacent carboxyl groups, and second, by the formation of ester links between the anhydride intermediate and cellulose. Fig. 1 shows the mechanism of BCD fixation to cotton via BTCA through the esterification reaction. This has been verified by researchers with Fourier transfer infrared (FTIR) spectroscopy. ${ }^{5}$ For bifunctional polycarboxylic acids such as malic acid or succinic acid, only one carboxyl group is said to be involved in esterification with cotton. ${ }^{6}$ Citric acid is cheaper than BTCA and also more eco-friendly, however, it is known to cause fabric yellowing. ${ }^{7}$ BTCA used at certain application concentrations is also known to give flame resistant properties to blends ${ }^{8}$ and to cotton ${ }^{9}$ (i.e., Class 1 flame retardant effect according to test method ASTM D1230). BTCA is also said to be more resistant to hydrolysis, and therefore, more wash durable as well. ${ }^{9,10}$

Sodium hypophosphite (SHPI) is a widely-used catalyst with BTCA since it gives almost no yellowing and good wrinkle recovery properties. It speeds up the process of BTCA esterification with cotton by weakening hydrogen bonds between the carboxylic groups. Use of SHPI reduces the temperature required for cyclic anhydride formation when compared to the use of BTCA alone. ${ }^{11}$ In general, SHPI is also considered an optimal BTCA catalyst in comparison with other catalysts, especially in terms of the durability of durable press performance. ${ }^{12,13}$

The amount of BCD, HP BCD, and MCT BCD fixation were assessed by simple gravimetric measurements and the well-known phenolphthalein test. Cotton fixed to BCD was characterized using FTIR-ATR spectroscopy and differential scanning calorimetry (DSC). These two techniques were only used for the BCD-treated cotton. Finally, durability of the attached $\beta$-cyclodextrins was analyzed by repeated laundering tests.

\section{Experimental}

Materials

The plain woven cotton (fabric density) $170 \mathrm{~g} / \mathrm{m}^{2}$ was obtained from wfk Testgewebe. BCD and HP BCD were obtained from Roquette. BTCA, sodium hydroxide, sodium carbonate, tris(hydroxymethyl)aminomethane (Tris), phenolphthalein, and SHPI were obtained from Sigma Aldrich. MCT BCD was obtained from CTD Inc. Demineralized water was used in all experiments.

\section{Various $\beta$-Cyclodextrin Treatments} Cotton fabrics were treated using the exhaustion method at room temperature (RT) with the liquor to cloth ratio (LCR) of 20:1. BCD treatment was done in a beaker where the required amounts of BTCA $(10,30$, or $60 \mathrm{~g} / \mathrm{L})$ and SHPI were added to the calculated liquor volume and stirred until they were dissolved. The required amount of BCD was added $(0,40,60,80$, or $100 \mathrm{~g} / \mathrm{L})$ and dissolved. Fabric samples were placed inside the liquor and stirred for $5 \mathrm{~min}$. After treatment, the fabric samples were pre-dried at $110^{\circ} \mathrm{C}$ for $10 \mathrm{~min}$, cured at $160^{\circ} \mathrm{C}$ for $5 \mathrm{~min}$, rinsed in water $\left(60^{\circ} \mathrm{C}\right.$, $5 \mathrm{~min}$ ), rinsed with tap water, and finally air dried.

The curing temperature was kept at $160{ }^{\circ} \mathrm{C}$, since it is known that anhydride formation with SHPI occurs at this temperature. ${ }^{14}$ The use of higher temperatures may lead to higher esterification (i.e., more crosslinking of BTCA), however, this would also lead to more tensile strength loss. ${ }^{15}$ The BTCA to SHPI molar ratio used was $1: 0.3 .{ }^{16} \mathrm{In}$ the literature, the BTCA to SHPI mass ratios of 3:1,11 2:1, ${ }^{17}$ and $1: 1^{18}$ were also reported. SHPI catalyst can be effective starting from $0.3 \%(3 \mathrm{~g} / \mathrm{L})$ to $11 \%$ concentrations. ${ }^{19} \mathrm{To}$ check the influence of curing conditions and the influence of the BTCA to SHPI ratio on the amount of BCD fixed on cotton, a series of trials with increased curing temperature

Fig. 1. Attachment of BCD to cotton with BTCA. ${ }^{5}$ Source reproduced with permission from Elsevier.

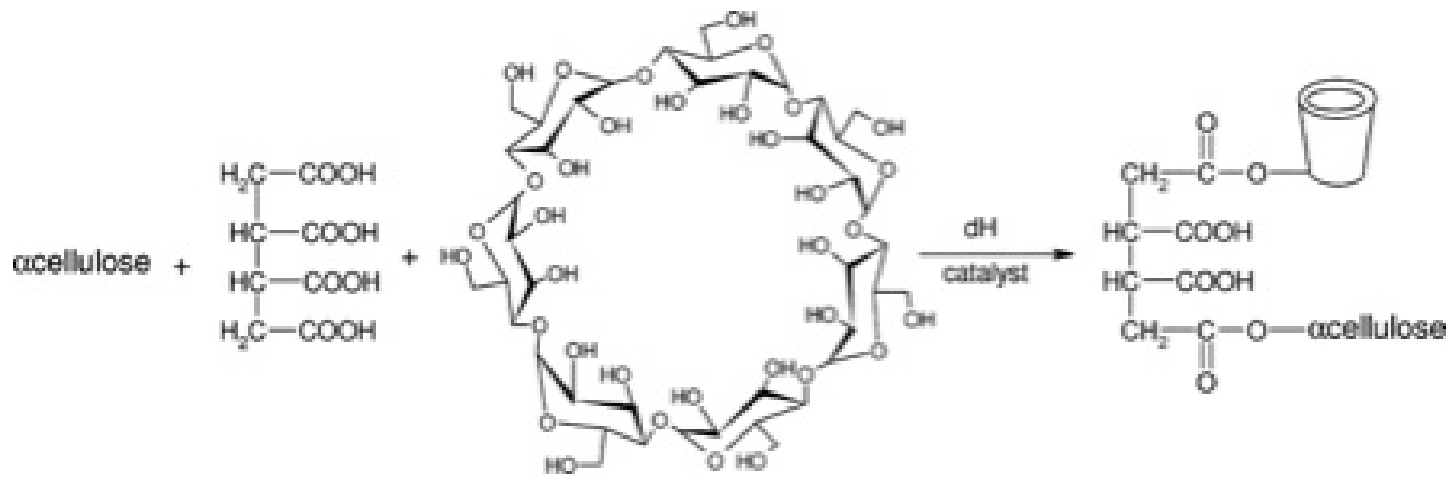


$\left(180^{\circ} \mathrm{C}\right)$ and increased BTCA to SHPI molar ratio (1:1) were performed and the fixation amount obtained was compared to the amount achieved under standard treatment conditions $\left(160^{\circ} \mathrm{C}\right.$, BTCA to SHPI molar ratio of 1:0.3).

For treatment with $\operatorname{HP} \operatorname{BCD}(0,40,60,80$, or $100 \mathrm{~g} / \mathrm{L})$, the same procedure was followed, with the exception that the amount of BTCA used was only $30 \mathrm{~g} / \mathrm{L}$.

For treatment with MCT BCD $(0,40,60,80$, or $100 \mathrm{~g} / \mathrm{L})$, the procedure was the same as above with the exception that no BTCA/SHPI was added and the treatment was performed in alkaline medium $(\mathrm{pH} 11,125 \mathrm{mM}$ sodium carbonate solution). The treatment time, pre-drying, curing at $160^{\circ} \mathrm{C}$, and sample rinsing after the treatment were the same as in the two previously mentioned cases.

\section{Analysis and Measurement}

Gravimetric Measurements

To assess the amount of $\beta$-cyclodextrin fixed, gravimetric measurements were made before and after sample treatment (Eq. 1). Before each measurement, samples were conditioned at $20^{\circ} \mathrm{C}$ and $65 \%$ relative humidity for $24 \mathrm{~h}$.

$$
W \%=\frac{W f-W b}{W b} \times 100 \%
$$

$\mathrm{W}_{b}$ is the sample weight before treatment and $\mathrm{W}_{f}$ is the sample weight after treatment.

\section{Quantification with Phenolphthalein}

The amount of $\beta$-cyclodextrin fixed onto a fabric can be estimated using an alkaline phenolphthalein solution. Phenolphthalein can complex within the $\beta$-cyclodextrin cavity. The absorbance of the alkaline phenolphthalein can be measured with UV-vis spectrophotometer at $550 \mathrm{~nm}$.

A calibration curve was made to plot the decrease in absorbance of phenolphthalein solution with the increase in concentration of $\beta$-cyclodextrin. For the calibration curve, a series of test tubes were set up, each containing a $5 \mathrm{~mL}$ solution $(V$ in $\mathrm{L}$ ). Each test tube contained $1 \mathrm{~mL}$ of varying concentrations of $\beta$-cyclodextrins ( $C$ in $g / L$ ) made in the buffer solution (Tris buffer solution, $0.05 \mathrm{M}, \mathrm{pH}$ 7), and 4 $\mathrm{mL}$ of phenolphthalein solution at a fixed concentration (in $\mathrm{g} / \mathrm{L}$ ). From the curve fit equation, a relationship between absorbance and concentration of $\beta$-cyclodextrins was determined. The concentration of phenolphthalein and sodium carbonate used were taken from the literature. ${ }^{20,21}$
The phenolphthalein working solution was prepared by preparing a $4 \mathrm{mM}$ stock solution of phenolphthalein in ethanol, and taking $1 \mathrm{~mL}$ of this stock and mixing it with $4 \mathrm{~mL}$ of ethanol and $95 \mathrm{~mL}$ of $125 \mathrm{mM}$ sodium carbonate solution. The $\mathrm{pH}$ of this $0.04 \mathrm{mM}$ phenolphthalein solution was 11 . For the fixed $\beta$-cyclodextrin quantification, $4 \mathrm{~mL}$ of this phenolphthalein working solution was added to $1 \mathrm{~mL}$ of Tris buffer solution (0.05 M, pH 7), and samples $(2.5 \mathrm{~cm} \times 2.5 \mathrm{~cm})$ of $\beta$-cyclodextrin treated fabric was put in this $5 \mathrm{~mL}$ solution. The final concentration of the $5 \mathrm{~mL}$ phenolphthalein in the test tubes was $0.032 \mathrm{mM}$. Since phenolphthalein can undergo photo-oxidation (sodium carbonate at the concentration used was supposed to stabilize it), the test tubes were covered with aluminum foil and kept for $2 \mathrm{~h}$ in a dark cabinet. The absorbance of the remaining solution was then measured at $550 \mathrm{~nm}$ using Cary 100 UV spectrophotometer (Agilent Technologies).

From the absorbances noted from the test tubes and the curve fit equation, the mass of $\beta$-cyclodextrin in the $5 \mathrm{~mL}$ of phenolphthalein solution and finally on the fabric could be estimated. The mass of the different $\beta$-cyclodextrins (BCD, HP BCD, and MCT BCD) fixed on cotton ( $F$ in $\mathrm{mg} / \mathrm{g}$ ) was calculated using Eq. 2.

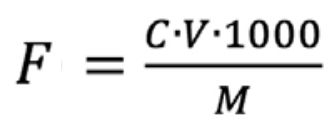

Eq. 2

$C$ is the $\beta$-cyclodextrin concentration measured in $\mathrm{g} / \mathrm{L}, V$ is volume in $\mathrm{L}$, and $M$ is the dry weight of fabric sample in $\mathrm{g}$.

To check for the influence of BTCA on phenolphthalein quantification of $\mathrm{BCD}$, homogenous absorbance tests were done with phenolphthalein and $\mathrm{BCD}$ solutions containing BTCA. A $0.04 \mathrm{mM}$ solution of phenolphthalein was made and divided into two beakers. In one beaker, $1 \mathrm{~g} / \mathrm{L}$ of BTCA was added. Then two series of test tubes were arranged and one was filled with $4 \mathrm{~mL}$ of phenolphthalein solution with BTCA and the other without the BTCA. BCD solutions $(1 \mathrm{~mL})$ of various concentrations made in $0.05 \mathrm{M}$ Tris buffer were then added to all the test tubes and the absorbances were then measured at $550 \mathrm{~nm}$ with the UV spectrophotometer.

\section{FTIR-ATR Spectroscopy}

BTCA crosslinks cotton through esterification reactions. The effectiveness of crosslinking various amounts of BTCA on cotton can be indirectly assessed using FTIR spectroscopy. Crosslinking effectiveness is expressed in terms of degree of esterification. The relative amount of ester formed on 
different BTCA-treated cotton fabrics is obtained from the ester peak intensity, while acid fixed to the fabric can be derived by the carboxylate anion peak intensity in FTIR spectroscopic measurements of these fabrics. The ratio between the two peaks, called the carbonyl band intensity ratio, gives the degree of esterification on the crosslinked cotton.

This method is based on the semi-quantitative assessment of degree of esterification by the measurement of the carbonyl band intensities. ${ }^{6,22,23}$ The resulting ester carbonyl band intensity ratio is correlated to the wrinkle recovery angle and tensile strength of fabric treated with BTCA. ${ }^{15}$ Samples are pre-treated with sodium hydroxide $(\mathrm{NaOH})$ or ammonia vapor before analysis. It was reported that the $\mathrm{NaOH}$ method of sample preparation is suitable only for the assessment of degree of esterification on BTCAtreated cotton and not for cotton crosslinked with other polycarboxylic acids. ${ }^{24}$ Pre-treatment of BTCA-treated cotton with hydrogen chloride $(\mathrm{HCl})$ vapor leads to the protonation of ionized carboxylate groups $\left(-\mathrm{COO}^{-}\right.$to $\left.-\mathrm{COOH}\right)$ on cotton. This consequently shows up as a new peak at $1720 \mathrm{~cm}^{-1}$ in FTIR spectroscopic analysis. This can be reversed with exposure of BTCA-treated cotton to ammonia vapor. ${ }^{25}$

In this work, FTIR-ATR spectroscopic measurements were performed to assess the influence of BCD fixation with BTCA on the formation of esters on cotton.

$\mathrm{BCD}$ concentrations were varied along with BTCA concentrations. The ester intensity of the fabrics were then checked at standard curing conditions (i.e., cotton samples were treated with $30 \mathrm{~g} / \mathrm{L}$ and $60 \mathrm{~g} / \mathrm{L}$ of BTCA and with $0 \mathrm{~g} / \mathrm{L}$ to $100 \mathrm{~g} / \mathrm{L}$ of $\mathrm{BCD}$ ), and the ester intensity on cotton was measured. The influence of curing conditions on formation of ester on BCD-treated cotton was also assessed (i.e., cotton samples were treated with $0 \mathrm{~g} / \mathrm{L}$ and $100 \mathrm{~g} / \mathrm{L}$ of $\mathrm{BCD}$ and 30 $\mathrm{g} / \mathrm{L}$ and $60 \mathrm{~g} / \mathrm{L}$ of BTCA at altered curing conditions (such as changed curing temperature and BTCA to SHPI ratio), and the ester intensity was measured again.

Preparation for FTIR-ATR analysis involved treating cotton fabric samples with $0.1 \mathrm{M} \mathrm{NaOH}$ for a minimum of $3 \mathrm{~min}$, washing off $\mathrm{NaOH}$ from the fabric, and then drying at $90^{\circ} \mathrm{C}$ for 10 min before FTIR-ATR measurements. Values given by the ammonia vapor method were not comparable to the $\mathrm{NaOH}$ method. Ammonia vapor can complex with the BCD cavity resulting in inconsistent measurements. Therefore, the $\mathrm{NaOH}$ method of pre-preparation was used for FTIR-ATR measurements in this paper.

FTIR-ATR spectra were obtained on a Bruker IFS 66/S spectrophotometer, equipped with Silver gate ATR cell employing a cylindrical Ge crystal $(\mathrm{n}=4.0)$ with a diameter of $7 \mathrm{~mm}$ and single reflection (SpectraTech). The samples were tightly pressed against a $\mathrm{Ge}$ crystal. Spectra were recorded over the range $4000-600 \mathrm{~cm}^{-1}$, with a resolution of $4 \mathrm{~cm}^{-1}$ and averaged over 128 spectra.

\section{Differential Scanning Calorimetry}

Differential scanning calorimetry (DSC) measurements were used to check the influence of BCD and BTCA treatment on thermal decomposition of cotton. Cotton samples were treated with $10 \mathrm{~g} / \mathrm{L}, 30 \mathrm{~g} / \mathrm{L}$, and $60 \mathrm{~g} / \mathrm{L}$ of BTCA, and $0 \mathrm{~g} / \mathrm{L}$ and $100 \mathrm{~g} / \mathrm{L}$ of $\mathrm{BCD}$ at various curing conditions. These measurements were made under a nitrogen flow of $20 \mathrm{~mL} /$ min. Samples were first held isothermally for $1 \mathrm{~min}$ at $25^{\circ} \mathrm{C}$, and then heated to $550{ }^{\circ} \mathrm{C}$ at the rate of $10^{\circ} \mathrm{C} / \mathrm{min}$. Cooling was done at the rate of $60^{\circ} \mathrm{C} / \mathrm{min}$. Sample weights for these measurements were around $9.3 \mathrm{mg}$ to $9.8 \mathrm{mg}$.

\section{Laundering Tests}

Cotton was treated with BCD, HP BCD and MCT BCD at $100 \mathrm{~g} / \mathrm{L}$ application concentration. BCD and HP BCD crosslinking with cotton was done with $30 \mathrm{~g} / \mathrm{L}$ of BTCA (and the earlier mentioned BTCA to catalyst ratio). Curing was done at $160{ }^{\circ} \mathrm{C}$ for $5 \mathrm{~min}$ for all samples as previously. These samples were laundered with $4 \mathrm{~g} / \mathrm{L}$ of AATCC Reference Detergent (without optical brighteners). Laundering was done at LCR of $50: 1$ at $60^{\circ} \mathrm{C}$ for $30 \mathrm{~min}$. After laundering, the samples were rinsed in tap water and then dried in the oven for $15 \mathrm{~min}$ at $110^{\circ} \mathrm{C}$. Six repeated laundering cycles were performed and the amount of fixation was assessed after each cycle.

\section{Results and Discussion}

\section{Gravimetric Measurements}

Weight gain (W\%) measurements vs. concentration of $\beta$-cyclodextrins for various treatments are shown in Figs. 2a and b. Fig. 2a shows weight gain results for treatments with $B C D$ at various BTCA concentrations, while Fig. $2 b$ shows results obtained for the treatments with all three types of $\beta$-cyclodextrins (BCD, HP BCD, and MCT BCD) used. Even when no $B C D$ was added, $W \%$ values on cotton increased with increased BTCA concentration (Fig. 2a). Use of $10 \mathrm{~g} / \mathrm{L}$ BTCA gave a steady increase in $\mathrm{W} \%$ values with increased $\mathrm{BCD}$ concentration. However, when greater amounts of BTCA (30 g/L and $60 \mathrm{~g} / \mathrm{L}$ ) were used, there was no steady corresponding increase in $\mathrm{W} \%$ values with increased $\mathrm{BCD}$ concentration. In the presence of $\mathrm{BCD}, \mathrm{W} \%$ values obtained for the treatments with $30 \mathrm{~g} / \mathrm{L}$ BTCA were lower than than for samples treated with $10 \mathrm{~g} / \mathrm{L}$ BTCA. All these facts imply that BTCA concentration predominantly influences $\mathrm{W} \%$ values. 
Fig. $2 \mathrm{~b}$ compares $\mathrm{W} \%$ values for cotton treated with various types of $\beta$-cyclodextrin. Comparison was made between BCD, HP BCD (both fixed with $30 \mathrm{~g} / \mathrm{L}$ BTCA), and MCT BCD treated fabrics. The influence of increased $\beta$-cyclodextrin concentration on $\mathrm{W} \%$ values was obvious only for cotton treated with BCD (Fig. 2a). HP BCD showed a slight loss in $\mathrm{W} \%$ values with increased concentration, while MCT BCD did not show any influence of increased concentration on the amount attached to cotton (almost constant $\mathrm{W} \%$ values). These results indicate that $\mathrm{W} \%$ measurements, due to their high standard deviation and inclusion of the crosslinker weight (for BCD and HP BCD), did not accurately correspond to the actual fixation amount.

Fig. 2. a) W\% values of cotton treated with varying concentrations of $B C D$ and 10,30 , and $60 \mathrm{~g} / \mathrm{L}$ BTCA. b) W\% values of cotton treated with varying concentrations and types of $\beta$-cyclodextrins. BCD and HP BCD were fixed to cotton with $30 \mathrm{~g} / \mathrm{L}$ BTCA, while MCT BCD was attached directly to cotton. For both a) and $b$ ), all values were an average of three measurements per value.

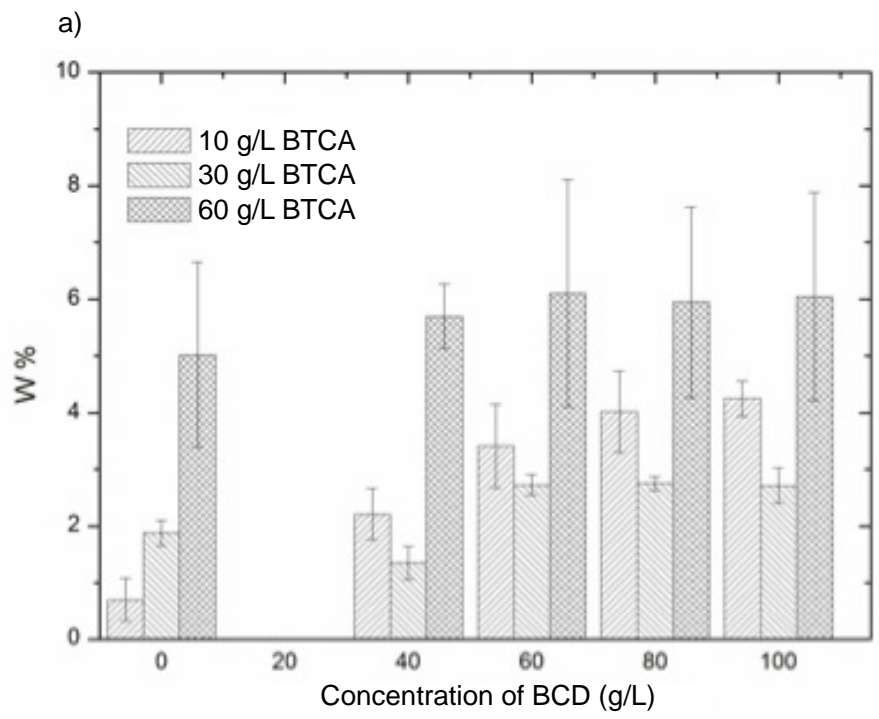

b)

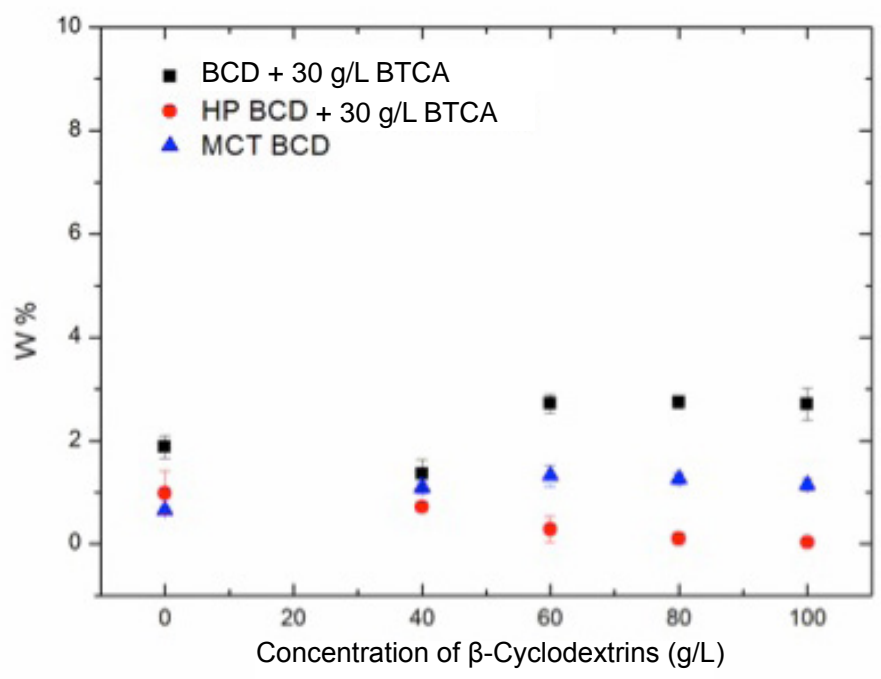

\section{Quantification of $\beta$-Cyclodextrins}

From the amount of $\beta$-cyclodextrin fixed on the cotton, shown in Fig. 3a as $F(\mathrm{mg} / \mathrm{g})$ against applied concentrations of $\beta$-cyclodextrin $(\mathrm{g} / \mathrm{L})$ with various concentrations of BTCA, there appeared to be no significant influence of crosslinker concentration on fixation amount. It was also noted that $30 \mathrm{~g} / \mathrm{L}$ of BTCA resulted in lower standard deviation in fixation values. The fixation of the different $\beta$-cyclodextrins on cotton is also given in moles/g of cotton in Table I.

\begin{tabular}{|c|c|c|c|}
\hline \multicolumn{4}{|c|}{$\begin{array}{l}\text { Table I. } \\
\text { Calculated Amount of Fixed } \beta \text {-Cyclodextrins on Cotton }\end{array}$} \\
\hline $\begin{array}{l}\text { Application } \\
\text { Concentration } \\
\text { (g/L) }\end{array}$ & $\begin{array}{l}\text { BCD with } 30 \\
\text { g/L of BTCA } \\
\text { (moles/g) }\end{array}$ & $\begin{array}{l}\text { HP BCD with } \\
30 \mathrm{~g} / \mathrm{L} \text { of BTCA } \\
(\text { moles } / \mathrm{g})\end{array}$ & $\begin{array}{l}\text { MCT BCD } \\
(\mathrm{moles} / \mathrm{g})\end{array}$ \\
\hline 0 & 0 & 0 & 0 \\
\hline 40 & $3.98 \times 10^{-6}$ & $1.29 \times 10^{-6}$ & $1.47 \times 10^{-6}$ \\
\hline 60 & $5.93 \times 10^{-6}$ & $1.59 \times 10^{-6}$ & $3.04 \times 10^{-6}$ \\
\hline 80 & $7.39 \times 10^{-6}$ & $1.94 \times 10^{-6}$ & $2.21 \times 10^{-6}$ \\
\hline 100 & $7.78 \times 10^{-6}$ & $2.40 \times 10^{-6}$ & $1.73 \times 10^{-6}$ \\
\hline
\end{tabular}

\begin{tabular}{|c|c|c|c|c|}
\hline $\begin{array}{l}\text { Table II. } \\
\text { Fixation } F \text { of } \\
\text { and BTCA Co }\end{array}$ & $\begin{array}{l}(100 \mathrm{~g} / \mathrm{L}) \text { at } \\
\text { ntrations }\end{array}$ & ferent Curir & onditions & \\
\hline Treatment Cond & & & $F(\mathrm{mg} / \mathrm{g})$ & SD \\
\hline $\begin{array}{l}\text { BTCA } \\
\text { Concentration } \\
(\mathrm{g} / \mathrm{L})\end{array}$ & $\begin{array}{l}\text { Curing } \\
\text { Temperature } \\
\left({ }^{\circ} \mathrm{C}\right)\end{array}$ & $\begin{array}{l}\text { BTCA:SHPI } \\
\text { Molar Ratio }\end{array}$ & & \\
\hline 60 & 160 & $1: 0.3$ & 7.82 & 2.05 \\
\hline 60 & 180 & $1: 0.3$ & 7.45 & 0.29 \\
\hline 60 & 180 & $1: 1$ & 5.95 & 0.57 \\
\hline 30 & 160 & $1: 0.3$ & 8.83 & 0.36 \\
\hline 30 & 180 & $1: 0.3$ & 9.10 & 0.81 \\
\hline 30 & 180 & $1: 1$ & 8.91 & 0.58 \\
\hline
\end{tabular}

The influence of curing conditions on the fixation of $\mathrm{BCD}$ on cotton was also noted for $30 \mathrm{~g} / \mathrm{L}$ and $60 \mathrm{~g} / \mathrm{L}$ of BTCA with $100 \mathrm{~g} / \mathrm{L}$ of $\mathrm{BCD}$. On changing the curing conditions to a higher curing temperature and with an increased BTCA to SHPI ratio, significantly increased fixation was not seen in the case of $30 \mathrm{~g} / \mathrm{L}$ of BTCA (Table II). When curing conditions were changed in the case of $60 \mathrm{~g} / \mathrm{L}$ of BTCA, no significant change in the amount of $\mathrm{BCD}$ fixation was noted with an increase in curing temperature to $180^{\circ} \mathrm{C}$. However, with the additional increase in the BTCA to SHPI ratio from 
Fig. 3. a) Amount of BCD fixed on cotton with varying applied concentrations of BCD and 10,30, and $60 \mathrm{~g} / \mathrm{L}$ of BTCA. b) Amount of $\beta$-cyclodextrins fixed on cotton treated with varying concentrations and types of $\beta$-cyclodextrins. BCD and HP BCD were fixed with $30 \mathrm{~g} / \mathrm{L}$ of BTCA, while MCT BCD was attached directly. For both a) and b), all values are an average of three measurements per value.

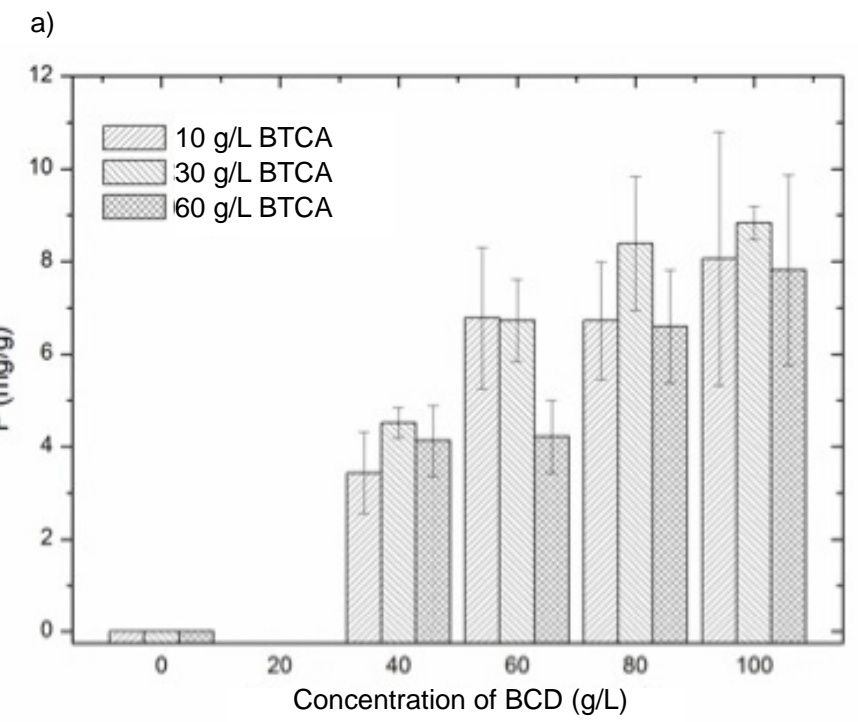

b)

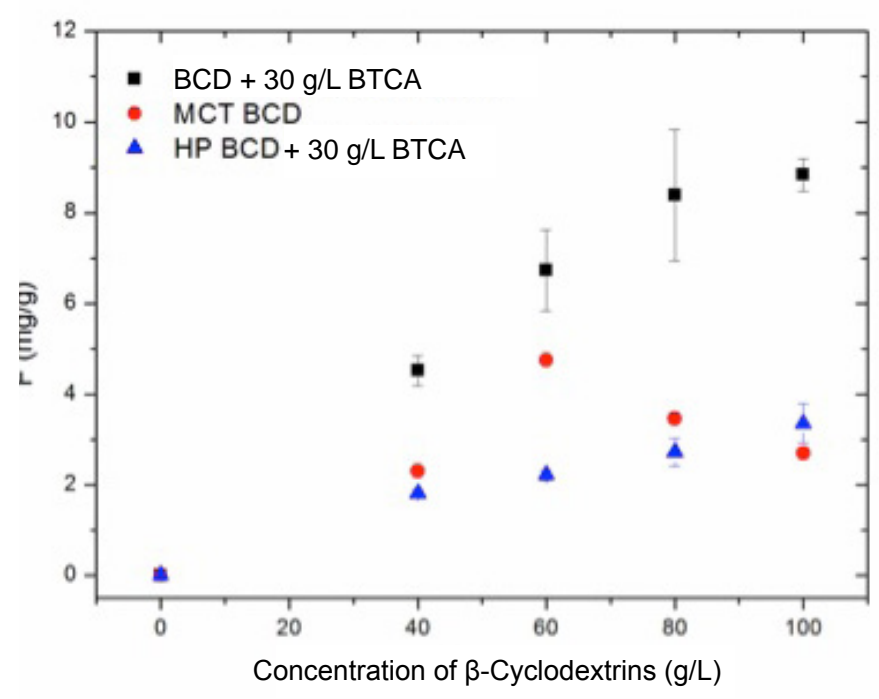

1:0.3 to $1: 1$ mole ratio at this higher curing temperature, the amount of BCD fixation was in fact reduced (Table II). From this data, even though a greater amount of BTCA was used, increased curing temperature and catalyst concentration may mean greater esterification, it may not mean increased fixation of BCD.
The amount of fixation was greatest for the BCD, followed by the other two derivatives of $\beta$-cyclodextrin (Fig. $3 \mathrm{~b}$ and Table I). For HP BCD, although the W\% measurements showed decreased $\mathrm{W} \%$ values with increased concentration of HP BCD applied, the measurement with phenolphthalein showed a linear increase in HP BCD fixed on cotton. The reason for the lower fixation of $\mathrm{HP}$ BCD as compared to $\mathrm{BCD}$ on cotton under the same given fixation conditions could be due to the long chain of the substituted 2-hydroxypropyl groups of HP BCD in place of hydroxyl groups in the anhydroglucopyranose units, ${ }^{3}$ which are less accessible for the required reaction. These substituted groups allow increased solubility of HP BCD in aqueous solution (solubility at RT was $100 \mathrm{~g} / \mathrm{L}$ ). However, these groups may not guarantee increased fixation to cotton since fixation is determined by the number of free $-\mathrm{OH}$ groups on the C6 position of the glucopyranose unit of $\beta$-cyclodextrin molecule available for esterification. ${ }^{26}$

An instability of the phenolphthalein measurements was noted as predicted during the quantification of BCD fixed on the fabrics in the presence and absence of BTCA. The results of the homogenous tests done with phenolphthalein and BCD in the presence and absence of BTCA can be seen in Fig. 4, where absorbance $A$ of phenolphthalein is shown against concentration of $\mathrm{BCD}(\mathrm{g} / \mathrm{L})$ in the presence and absence of BTCA. In the presence of BTCA, the absorbance (A) values of the phenolphthalein solutions increased slightly, however, the readings stabilized with increased BCD concentration. The slight phenolphthalein measurement instability noted above was therefore ignored since this instability appeared to resolve when the amount of BCD fixed on the fabrics increased.

Fig. 4. Influence of BTCA on phenolphthalein in homogenous solution containing $\mathrm{BCD}$. All values are an average of three measurements per value.

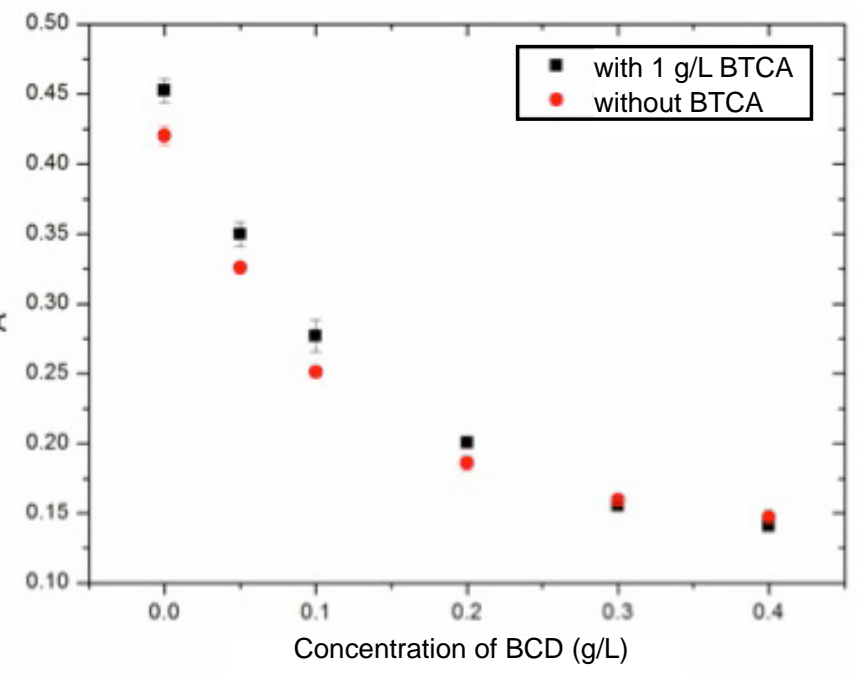




\section{FTIR-ATR}

FTIR-ATR spectroscopic analysis was performed to determine if BTCA esterification of cotton fabric was influenced by the addition of BCD. For esterified cotton, the $1720 \mathrm{~cm}^{-1}$ peak represents the overlap of the carbonyls $(\mathrm{C}=\mathrm{O})$ from the acid and the ester of BTCA. Treatment with $\mathrm{NaOH}$ converts the acid of BTCA on the fabric to carboxylate anion resulting in a new increased peak at $1570 \mathrm{~cm}^{-1}$. After complete conversion of acid to carboxylate anion with $\mathrm{NaOH}$, intensities of the $1720 \mathrm{~cm}^{-1}$ peak reflect the total ester on the fabric. The esterification degree of the fabric was calculated by dividing the two mentioned intensities. The resulting number is the average number of ester groups formed per BTCA molecule. This result indicates the effectiveness of BTCA as a crosslinking agent or degree of esterification. For all FTIR-ATR data, the spectra was normalized for the $1313 \mathrm{~cm}^{-1}$ peak. Present experiments only dealt with data from the $1720 \mathrm{~cm}^{-1}$ (ester intensity) peak.

Figs. $5 \mathrm{a}$ and $\mathrm{b}$ shows the FTIR-ATR spectra of cotton fabrics treated with different concentrations of $\mathrm{BCD}$ and with 60 $\mathrm{g} / \mathrm{L}$ and $30 \mathrm{~g} / \mathrm{L}$ of BTCA. The differences in the ester peak intensity can be seen among the various fabrics. This could not be observed in the FTIR-ATR spectra of cotton treated with $10 \mathrm{~g} / \mathrm{L}$ BTCA (spectra not shown here).

Fig. $5 c$ shows the ester carbonyl band $\left(1720 \mathrm{~cm}^{-1}\right)$ intensity normalized at $1313 \mathrm{~cm}^{-1}$ of cotton fabrics treated with BTCA and $\mathrm{BCD}$ under various curing conditions. The ester band intensity represents the total amount of ester in the fabricester groups between cellulose and single-bonded acid molecules and ester groups crosslinking the cellulose and BCD molecules. Crosslinking occured quite randomly on cotton in the presence of BTCA due to the presence of the different mono- or di-esters of BTCA. With BCD included, additional permutations and combinations, such as $\mathrm{BCD}$ BTCA, BCD-BTCA-BCD, cotton- BTCA, cotton-BTCAcotton, cotton-BTCA-BCD, BCD-BTCA-cotton-BTCABCD, cotton-BTCA-BCD-BTCA-cotton, were expected. ${ }^{5,27}$ The first two combinations listed were washed away during the rinsing step.

The ester intensity with increased BCD application concentration with $30 \mathrm{~g} / \mathrm{L}$ and $60 \mathrm{~g} / \mathrm{L}$ of BTCA is given in Table III. The ester intensity was slightly more when $60 \mathrm{~g} / \mathrm{L}$ was used as compared to $30 \mathrm{~g} / \mathrm{L}$ BTCA use. A trend of reduced ester intensity with increased $\mathrm{BCD}$ application concentration was noted. The total amount of ester formed on the fabric increased with increased curing temperature or increased BTCA to SHPI ratio as expected (Fig. 5c).

However, the addition of BCD in each case seemed to reduce this peak intensity. Therefore when BCD was added to the system, the relative degree of ester formation was reduced as compared to when only BTCA was present.

\begin{tabular}{|c|c|c|c|}
\hline \multicolumn{4}{|c|}{$\begin{array}{l}\text { Table III. } \\
\text { FTIR Ester Peak Intensity with Different Concentrations } \\
\text { of BTCA and BCD }\end{array}$} \\
\hline $\begin{array}{l}\text { BTCA } \\
\text { Concentration } \\
(\mathrm{g} / \mathrm{L})\end{array}$ & $\begin{array}{l}\text { BCD Application } \\
\text { Concentration } \\
(\mathrm{g} / \mathrm{L})\end{array}$ & $\begin{array}{l}\text { Ester Peak } \\
\text { Intensity }\left(\mathrm{cm}^{-1}\right)\end{array}$ & SD \\
\hline 30 & 0 & 0.372 & 0.029 \\
\hline 30 & 40 & 0.346 & 0.021 \\
\hline 30 & 60 & 0.334 & 0.022 \\
\hline 30 & 80 & 0.296 & 0.016 \\
\hline 30 & 100 & 0.291 & 0.013 \\
\hline 60 & 0 & 0.390 & 0.007 \\
\hline 60 & 40 & 0.393 & 0.058 \\
\hline 60 & 60 & 0.357 & 0.023 \\
\hline 60 & 80 & 0.351 & 0.057 \\
\hline 60 & 100 & 0.343 & 0.007 \\
\hline
\end{tabular}

Anhydride intensities at $1782 \mathrm{~cm}^{-1}$ and $1852 \mathrm{~cm}^{-1}$ showed that with increasing BCD application concentration, these intensities were reduced when $30 \mathrm{~g} / \mathrm{L}$ of BTCA was used, with a mixed trend when $60 \mathrm{~g} / \mathrm{L}$ of BTCA was used (Table IV). If anhydride intensities had increased while ester intensities decreased, it could have been said that lower esterification was due to lower mobility of the anhydrides intermediate formed to access the cellulosic hydroxyl groups. This is known to happen if the molecular weight of a polycarboxylic acid is quite large..$^{28}$ Since this was not the case, this effect occurred unrelated to formation of the anhydride intermediate.

Reactivity of carboxylic acids and alcohols towards esterification are limited by steric hindrances. ${ }^{29}$ Steric hindrances in BCD can have an influence on cellulosic surface grafting. ${ }^{30}$ Therefore, steric hindrances could have led to the reduction in ester formation between BTCA, BCD, and cellulose when compared to ester formation with only BTCA and cellulose, resulting in less BCD crosslinking.

The degree of esterification increased with BTCA amount, therefore in general, the ester carbonyl band intensity ratio increased with increased BTCA concentration. ${ }^{23,24}$ The ester linkages were homogenously spread within the fabric, while the carboxylates had higher concentrations on the outer surface rather than in the fabric interior. ${ }^{22}$ Therefore, FTIR- 
Fig. 5. a) FTIR-ATR spectra of cotton samples treated with $60 \mathrm{~g} / \mathrm{L}$ BTCA; (a) untreated cotton and cotton treated with (b) 0 , (c) 40, (d) 60, (e) 80, and (f) $100 \mathrm{~g} / \mathrm{L}$ BCD respectively. All samples pretreated with $0.1 \mathrm{M} \mathrm{NaOH}$ prior to measurement. b) FTIR-ATR spectra of cotton samples treated with $30 \mathrm{~g} / \mathrm{L}$ BTCA and BCD. The legend shows the BCD application concentration used. c) Normalized ester peak intensity with change in curing temperature and BTCA:SHPI mole ratio shown in brackets. BCD applied was $100 \mathrm{~g} / \mathrm{L}$, and $30 \mathrm{~g} / \mathrm{L}$ and $60 \mathrm{~g} / \mathrm{L}$ of BTCA were used. All readings were an average of three samples. a)

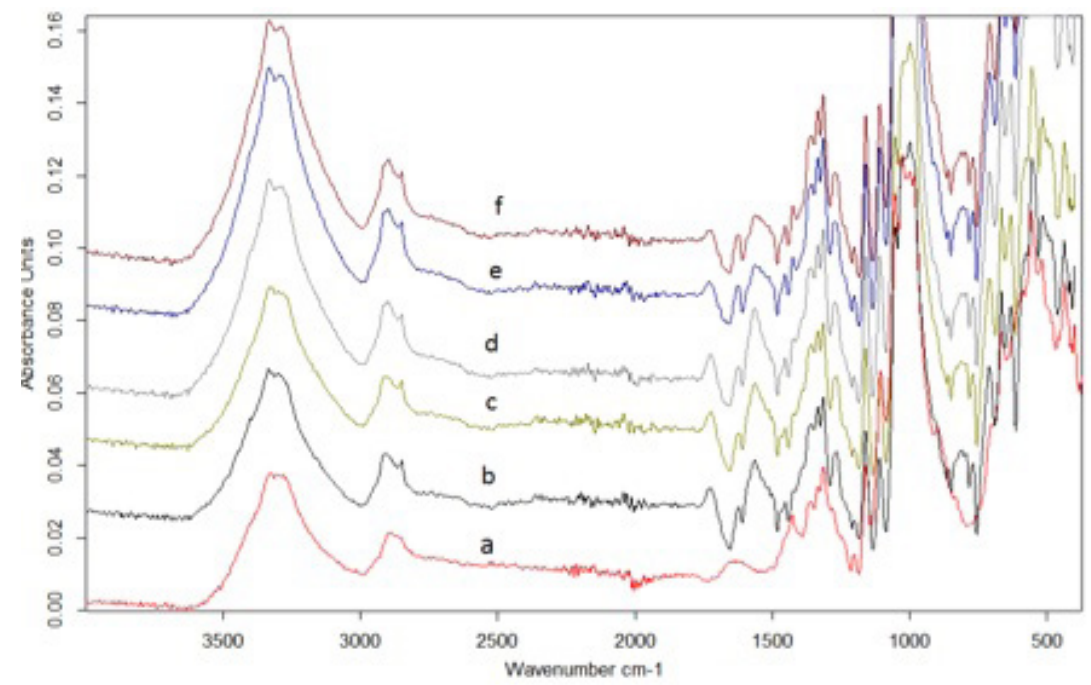

b)

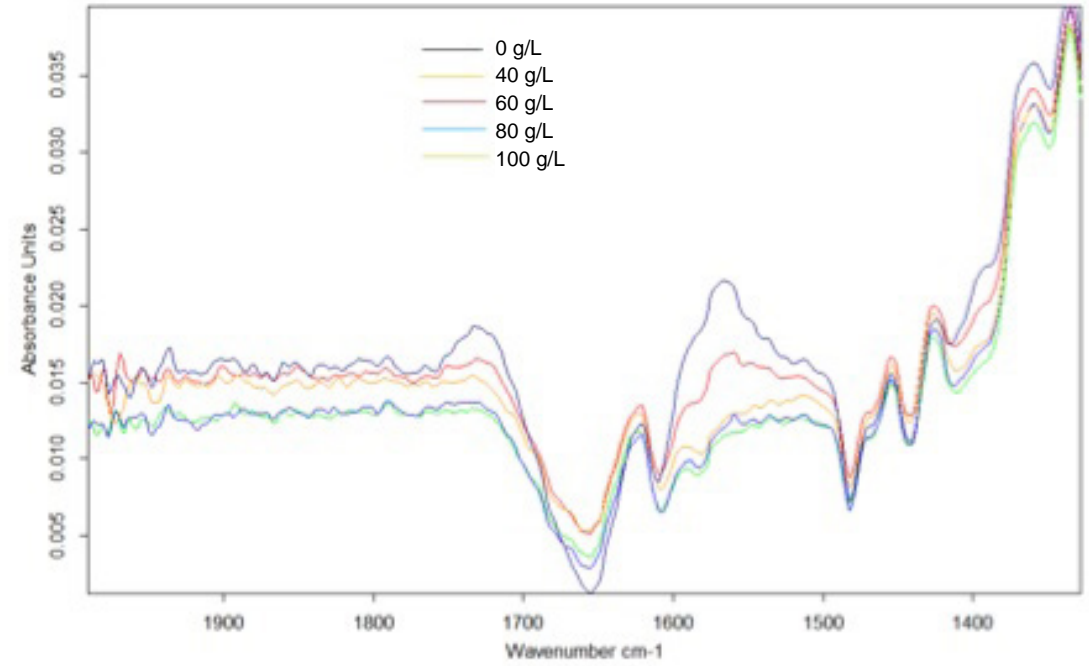

c)

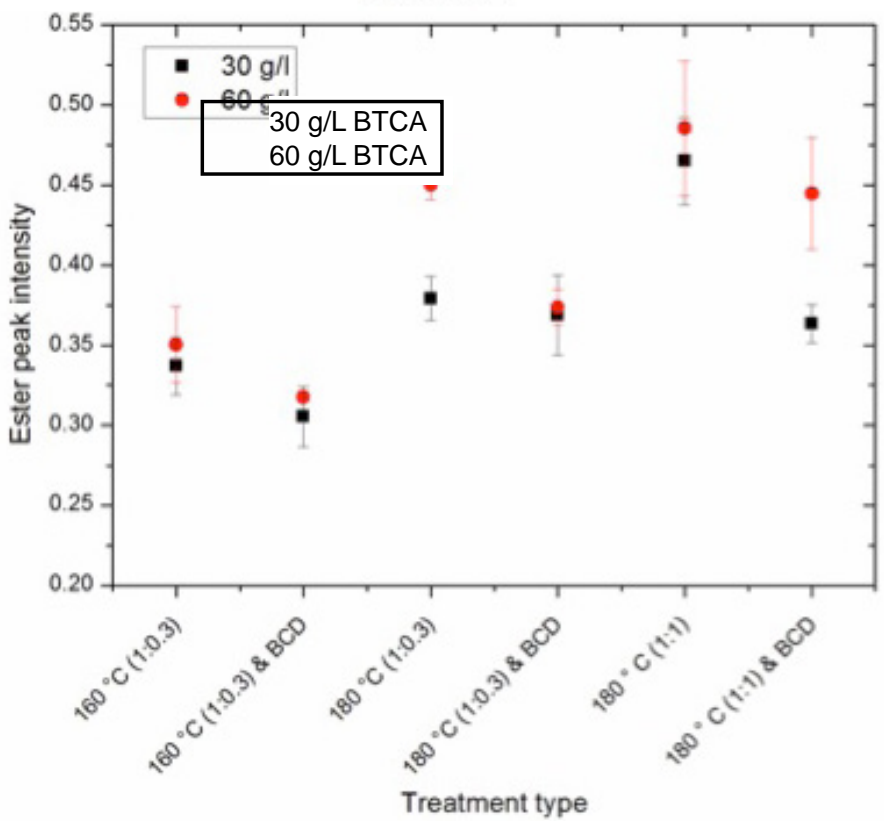


ATR spectroscopy for calculation of the ester carbonyl band intensity ratio was not used since FTIR-ATR spectroscopy is a near surface analysis technique. Use of the carboxylate intensity for degree of esterification calculations would lead to erroneous results.

\begin{tabular}{|c|c|c|c|c|c|}
\hline \multicolumn{6}{|c|}{$\begin{array}{l}\text { Table IV. } \\
\text { FTIR Anhydride Intensities with Different Concentration } \\
\text { of BTCA and BCD }\end{array}$} \\
\hline $\begin{array}{l}\text { BTCA } \\
\text { Concentration } \\
(\mathrm{g} / \mathrm{L})\end{array}$ & $\begin{array}{l}\text { BCD } \\
\text { Application } \\
\text { Concentration } \\
(\mathrm{g} / \mathrm{L})\end{array}$ & $\begin{array}{l}\text { Anhydride } \\
\text { Peak } \\
\text { Intensity } \\
\left(1782 \mathrm{~cm}^{-1}\right)\end{array}$ & SD & $\begin{array}{l}\text { Anhydride } \\
\text { Peak } \\
\text { Intensity } \\
\left(1852 \mathrm{~cm}^{-1}\right)\end{array}$ & SD \\
\hline 30 & 0 & 0.341 & 0.018 & 0.346 & 0.022 \\
\hline 30 & 40 & 0.337 & 0.016 & 0.339 & 0.015 \\
\hline 30 & 60 & 0.323 & 0.018 & 0.332 & 0.023 \\
\hline 30 & 80 & 0.300 & 0.017 & 0.304 & 0.020 \\
\hline 30 & 100 & 0.295 & 0.022 & 0.296 & 0.023 \\
\hline 60 & 0 & 0.302 & 0.024 & 0.315 & 0.020 \\
\hline 60 & 40 & 0.334 & 0.016 & 0.341 & 0.021 \\
\hline 60 & 60 & 0.300 & 0.038 & 0.305 & 0.028 \\
\hline 60 & 80 & 0.311 & 0.041 & 0.315 & 0.038 \\
\hline 60 & 100 & 0.309 & 0.012 & 0.311 & 0.013 \\
\hline
\end{tabular}

\section{Differential Scanning Calorimetry (DSC)}

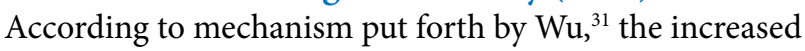
amount of ester on cotton can lead to flame resistanceesterification of the C-6 hydroxyl of cotton can prevent the formation of levoglucosan by reducing cotton depolymerization. Tetracarboxylic acid esterification leads to increased thermal activation energy and thermal stability, and greater char content (due to the increased carboncarbon network).

DSC spectra can show temperature and heat release changes in materials during pyrolysis. In the current work, the untreated cotton sample showed an endothermic peak around $370{ }^{\circ} \mathrm{C}$ due to char formation. For flame retardant treated cotton, thermal decomposition temperatures measured by DSC were lowered by a significant degree indicating the influence of flame retardants. ${ }^{32}$ The heat flow curve of all treated samples showed a small endothermic peak shift (Figs. 6a and b). However, no significant decomposition temperature differences were noted between the DSC curves of cotton samples treated with BTCA and with BCD when compared with native cotton. A slight, unrepeatable shift was noted when curing conditions were increased in some cases. Additional tests using a microscale combustion calorimeter (not shown here) showed no significant differences between the various treatments on cotton.

Fig. 6. a) DSC figures of treated and untreated cotton. b) DSC figures of cotton treated with and without $\mathrm{BCD}$ at various curing conditions. Legends for $\mathrm{a}$ ) and $\mathrm{b})$ include BTCA concentration $(\mathrm{g} / \mathrm{L}), \mathrm{BCD}$ concentration $(\mathrm{g} / \mathrm{L})$, BTCA: SHPI mole ratio, and curing temperature $\left({ }^{\circ} \mathrm{C}\right)$.

a)

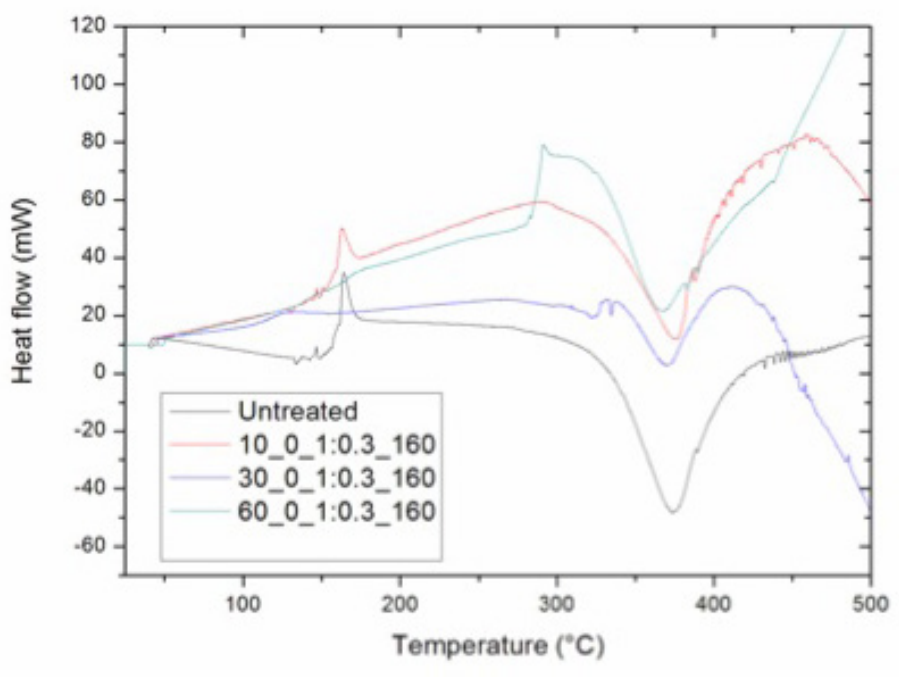

b)

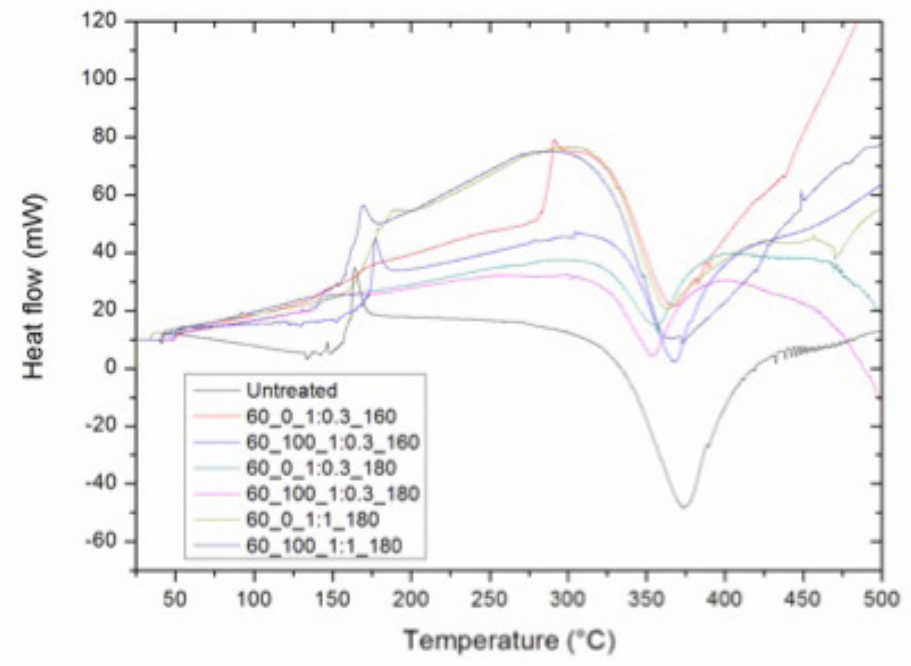




\section{Laundering Tests}

Rigourous laundering tests were performed showing that the amount of $\beta$-cyclodextrin fixed on the cotton reduced significantly with each wash cycle. Laundering conditions were taken from the list prescribed in the ISO $105 \mathrm{C} 06$ standard. MCT BCD was entirely removed after only one wash, while BCD and HP BCD lasted for a few washes (Fig. 7). Lower washfastness of ester linkages can be expected in the presence of BCD and HP BCD in comparison with crosslinking of only BTCA with cotton. With only BTCA attached, all the ester bonds (one to three formed) crosslink only with cotton, while attached BCD or HP BCD have at least one ester linkage remote from the cotton portion of the molecule. Apart from this, the addition of BCD into the system shows that the ester formation is also lowered (seen by the reduced ester intensity) in the system as compared to crosslinking with only BTCA, probably due to steric factors. These two factors result in the lower washfastness of the $\beta$-cyclodextrins fixed with BTCA to cotton. However, the reason for low wash durability of MCT BCD was not clear since the monochlorotriazinyl groups were expected to be covalently bound to cotton. The phenolphthalein method of quantification may lead to under estimation of $\beta$-cyclodextrins fixed onto cotton. This would be due to steric hindrance of surface $\beta$-cyclodextrin molecules preventing phenolphthalein molecules from entering $\beta$-cyclodextrins fixed inside the fabric. ${ }^{30}$ This direction of research needs further investigation. Some preliminary results with washing at lower temperatures and without detergent show better washfastness than observed here.

Fig. 7. Influence of increasing number of wash cycles on $\beta$-cyclodextrins functionalized cotton.

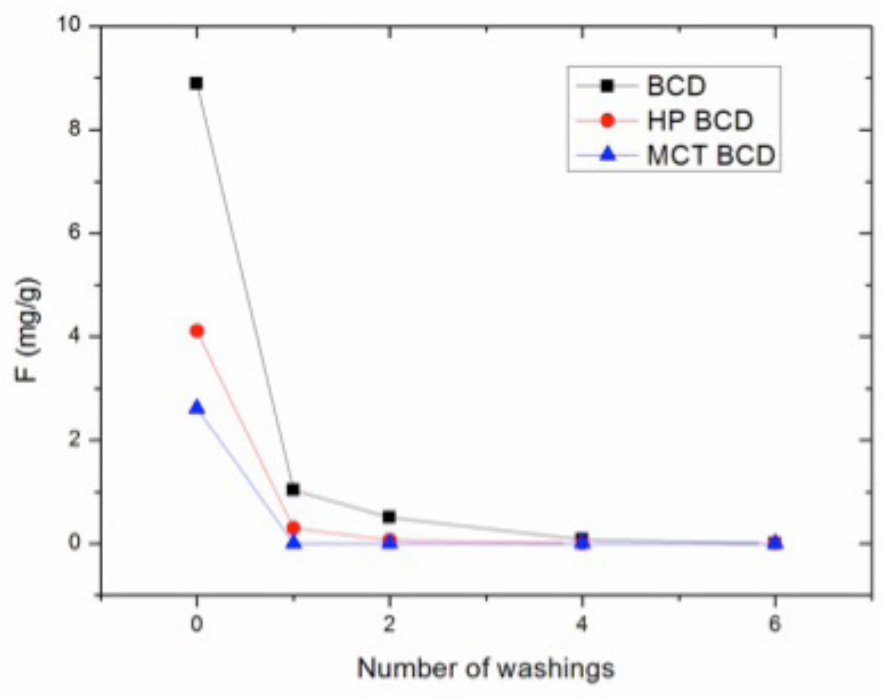

\section{Conclusions}

The results of this investigation show that $\beta$-cyclodextrin (BCD) and two $\beta$-cyclodextrin derivatives (HP BCD and MCT BCD) were successfully attached to cotton. Attachment of BCD with BTCA on cotton showed a greater amount of fixation than when MCT BCD and HP BCD were used. Varying the amount of the BTCA crosslinker did not have a significant influence on the amount of fixation of $\beta$-cyclodextrins on cotton under the curing conditions used. FTIR-ATR spectroscopic measurements showed that the total amount of ester formed on the fabric was reduced by addition of BCD in comparison to the only BTCAtreated cotton. DSC measurements showed no significant differences in the thermal decomposition peak temperatures due to BTCA treatment on cotton as compared to nontreated cotton, however all treated fabrics showed a small endothermic shift in the heat flow curve.

Laundering tests showed that, under severe washing conditions, the amount of $\beta$-cyclodextrins on cotton was drastically reduced with each wash cycle indicating poor washfastness. Despite poor wash durability, this technology can be used in applications where washing is infrequent, such as in wound dressings, where a BCD-treated textile could host antibacterial molecules for slow and controlled release.

\section{Acknowledgements}

The authors would like to thank Clemens Padberg (MTP, University of Twente), Bert Vos (Production Technology, University of Twente), and Jacob S. Lopulissa, Salina Sarwari, and Ernest Cichomski (ETE group, University of Twente).

\section{References}

1. Szejtli, Jozsef, ChemInform, Vol. 29, No. 39, 1998, pp1743-1754.

2. Loftsson, T. and M. E. Brewster, Journal of Pharmaceutical Sciences, Vol. 85, No. 10, 1996, pp1017-1025.

3. Roquette, Technical Sheet, Kleptose Betacyclodextrins and Hydroxypropyl Betacyclodextrins.

4. www.cyclodextrin.org/cdpdf/cs_w7_mct.pdf, last accessed January 2013.

5. Medronho, B., R., et al., Carbohydrate Polymers, Vol. 93, No. 1, 2012, pp324-330.

6. Yang, C. Q., Textile Research Journal, Vol. 61, No. 8, August 1991, pp433-440.

7. Lu, Yun, and Charles Q. Yang, Textile Research Journal, Vol. 69, No. 9, September 1999, pp685-690.

8. Blanchard, E. J., E. E. Graves, and P. A. Salame, Journal of Fire Sciences, Vol. 18, No. 2, 2000, pp151-164.

9. Wu, X., C. Q. Yang, and Q. He, Cellulose, Vol. 17, No. 4, 2010, pp859-870.

10. Welch, C. M., Textile Research Journal, Vol. 58, 1988, pp480-486.

11. Xiaohong, G., and C. Q. Yang, Textile Research Journal, Vol. 70, No. 1, January 2000, pp64-70. 
12. Welch, C. M., Textile Chemist and Colorist, Vol. 22, No. 5, May 1990, pp13-16.

13. Trask-Morrell, B. J. and B. A. K. Andrews, Textile Research Journal, Vol. 62, No. 3, March 1992, pp144-150.

14. Gillingham, E. L., D. M. Lewis, and B. Voncina, Textile Research Journal, Vol. 69, No. 12, December 1999, pp949-955.

15. Wei, W., and C. Q. Yang, Textile Research Journal, Vol. 69, No. 2, February 1999, pp145-151.

16. Lee, E. S., and H. J. Kim, Journal of Applied Polymer Science, Vol. 81, No. 3, 2001, pp654-661.

17. Jocić, D., A. Tourrette, and P. Krizman Lavrić, Biopolymers, edited by M. M. Elnashar, SCIYO, Rijeka, Croatia, 2010.

18. Šauperl, O. and K. Stana-Kleinschek, Textile Research Journal, Vol. 80, No. 4, April 2010, pp383-392.

19. Welch, C. M. and B. K. Andrews, US Patent Number 4,936,865, 1990.

20. Basappa, Channa, Pramila Rao, and D. Narasimha Rao, International Journal of Food Science \& Technology, Vol. 33, No. 6, 1998, pp517-520.

21. Agrawal, P. B. and M. M. C. G. Warmoeskerken,. Journal of Applied Polymer Science, 2012.

22. Yang, C. Q., Textile Research Journal, Vol. 61, No. 5, May 1991, pp298-305.

23. Sauperl, O., K., et al., Croatia Chemica Acta, Vol. 76, No. 4, 2003, pp293-298.

24. Morris, N. M., E. A. Catalano, and B. A. K. Andrews, Cellulose, Vol. 2, No. 1, 1995, pp31-39.

25. Chung, C., M. Lee, and E. K. Choe, Carbohydrate Polymers, Vol. 58, No. 4, 2004, pp417-420.

26. Blanchemain, N., et al, Acta Biomaterialia, Vol. 7, No. 1, 2011, pp304-314.

27. Si, Hongyan, et al., Wood Science and Technology, Vol. 47, No. 3, 2013, pp601-613.

28. Yang, Charles Q, and Xilie Wang, Journal of Polymer Science Part A: Polymer Chemistry, Vol. 35, No. 3, 1997, pp557-564.

29. Hoydonckx, Hans E., et al., Topics in Catalysis, Vol. 27, Nos. 1-4, 2004, pp83-96.

30. Wang, Ting, Bin Li, and Hongyan $\mathrm{Si}$, Cellulose Chemistry and Technology, Vol. 47, Nos. 1-2, 2013, pp37-47.

31. Wu, X., Ph.D. Thesis, The University of Georgia, 2008

32. Zhu, Ping, Journal of Analytical and Applied Pyrolysis, Vol. 71, No. 2, 2004, pp645-655.

\section{Author}

Usha Rashmi Bhaskara is a Ph.D. student at the EFSM group, University of Twente. Her research interests include $\beta$-cylcodexterin attachment to textiles and antimicrobial functionalization.

Usha Rashmi Bhaskara, EFSM Group, Faculty of Engineering \& Technology, University of Twente, Driernerlolaan 5, Enschede 7522 NB, The Netherlands; phone +31 534894112; u.r.bhaskara@utwente.nl. 